\title{
The Cultural Transmission of Raise the Red Lantern: The Representation of Symbolism
}

\author{
Xiaoyan Zhang* \\ Department of Sociological Studies, The University of Sheffield, Sheffield, United Kingdom \\ ${ }^{*}$ Corresponding author. Email: xzhang259@sheffield.ac.uk
}

\begin{abstract}
Film is a popular media content in today's society, always portraying political, cultural, social and philosophical ideologies by virtue of its representation, reality and immediacy. With its characteristics of the richness of visual images, films have the propagation effect to spread the narration of cultural diversity. This short research paper focuses on the representation of the aesthetics, editing and narrative of the traditional Chinese film Raise the Red Lantern (1991) to explore the inner meaning. With its unique combination of oriental visual aesthetics and folk Chinese culture, the film has become one of the dominant Asian films in the global film market. More importantly, there are a large number of metaphorical symbols in this film. These objects are inextricably related to the plot's development, as well as delivering a cultural transmission to international audiences. This film is worth doing more deeper research on the relationships of semiotics, symbolism, and cultural transmission for individuals.
\end{abstract}

Keywords: Film, Symbols, Semiotics, Symbolism, Cultural Transmission

\section{INTRODUCTION}

Films have the property of visual communication and are more expressive than other media contents, relying on the representational, tangible and visual characteristics to determine the wide audience for films as a communication medium. In addition, films convey a number of unique communication methods, including pictorial, aural, narrative, metaphorical and many other routes of transmission. Raise the Red Lantern is a Chinese film directed by Yimou Zhang in 1991, who is a famous director in China and across the globe, as well as a representative of China's fifth film generation filmmakers.

Raise the Red Lantern demonstrates the narrative of Songlian, a young lady who becomes one of a wealthy man's five concubines, and the journey she takes, from ignorance to habituation, to getting financial support from her husband, and eventually despair in the family during the period of the Republic of China. This story is a microcosm of the warlord era, which depicts a household life under a feudal social background to audiences.

This research paper delivers an analysis of the symbolism and cultural transmission of Raise the Red Lantern, which mainly focuses on the narrative itself, diverse visual objects, and the communication between them. Furthermore, the research topic is related to an interdisciplinary mixture of film studies and cinematic sociology, which provides a pluralistic viewpoint for audiences to perceive the spread of Raise the Red Lantern [1].

Numerous previous research papers have established that the visual elements and symbols to analyse, which are connected to aesthetic perspective instead of cultural level [2-3]. For instance, Luo only concentrates on the artistic language of Raise the Red Lantern and focuses on the use and characteristics of colours [3]. In addition, other essays have been written from a gender studies perspective to expose the inequalities and patriarchal suppression that women faced in China's feudal social system. Both studies focus on the tragic fate of women as the central subject, analysing each female character in turn, thus demonstrating that women, regardless of their status, are assimilated into a decadent cultural context and can never escape the feudal system [4-5]. However, few research papers concern the cultural communication of Raise the Red Lantern. This research paper makes a combination of symbolic analysis and cultural transmission narration. It uses symbolic metaphors to illustrate cultural communication in which the relationship between them is close and progressive. Thus, 
this research paper critically evaluates symbolism and communication in a bid to address the gap.

According to the particularity of the research object, this research combines aesthetics analysis, narrative analysis and symbolism research method. Aesthetics analysis includes mise-en-scène, costumes, sound, editing and several other elements. It is a familiar method for individuals to analyse a film. This paper uses aesthetics analysis to discover a number of significant visual objects, diegetic and non-diegetic sound and editing, which is more intuitive for people to understand the film. Moreover, the narrative method is a well-known and traditional research method to see how narrative construction reflects plot and psychological insight. It complements the aesthetic analysis of visual objects by offering a multi-dimensional view of the representations. At the same time, a symbolism research method is also used. It makes an interactive relationship with encoding and decoding theory in semiotics in the interpretation of visual signs. This method is superimposed on aesthetics and easily exposes the inner meanings [6].

Raise the Red Lantern is a microcosm of a corner of feudal China. From the early days of showing the film, it was praised by the public and film academics, and gradually became a masterpiece of Chinese cinema and even of East Asian cinema. It is through these significant audiovisual languages and prominent filmmaking to convey a symbolic representation. Therefore, this thesis documents the representation of symbolism of Raise the Red Lantern from several aspects (e.g., visual objects, soundtracks, and editing), which successfully achieves a cultural transmission effect, allowing wider international audiences to gain some understanding of the traditional Chinese aesthetic style and folk culture of the early years.

\section{VISUAL OBJECTS}

Raise the Red Lantern provides a highly visual aesthetics. A number of different visual objects serve as symbols to deliver a metaphorical representation to audiences. They mainly highlight the development of the plot and numerous potential folk cultural traditions in this film.

\subsection{Red Lanterns}

The red lanterns are originally festive decorations, but they are enveloped by a melancholic and sorrowful colour throughout Raise the Red Lantern. For example, the process of the red lanterns being lit, extinguished, and sealed in several montage shots implies the twisted fate of these women. Moreover, the contrast of the background settings and red lanterns also has a significant visual shock and emotional impact on the audience, because of the juxtaposition between the sight of extremely saturated red lanterns and the pure snowy backdrop [7].
These red lanterns are core signified symbols, which convey that the uncontrollable lives of these concubines. The director used red lanterns throughout the whole film to satirise the unshakeable power of patriarchy and the fragility of women as we see that even though all the lanterns are extinguished at the end of the film, the female character remains trapped in the courtyard [8]. In general, the perpetual patriarchal oppression faced by women corresponds to the endless darkness in the tail of Raise the Red Lantern.

\subsection{Feet}

In Raise the Red Lantern when the servants massage the concubine's feet, it means that they will serve their husband. The feet represent sexual desire and the number of times they are massaged represents their standing in this family. Furthermore, feet are intimately related to female characters, revealing the intersected social issues and stereotyped social milieu, in which women experienced physical and psychological strain from this social system throughout that era.

Feet decodes the status of women during that period. They embody feminine self-objectification and selfnegation through feet, owing to women's innate obedience to men's demands in a long-standing misogynistic culture. Overall, women are objects that existed for the male subject.

\subsection{Costumes}

In Raise the Red Lantern, the importance of costumes cannot be ignored. When Songlian first appears in the film, she is dressed in a student uniform consisting of a black skirt and white dress. The plain attire serves as a visual introduction to the cultural and social background of that era. Many young Chinese studied in Japan during the time of the Northern Warlords because of the influence of the local culture and politics. A majority of girls are happy to wear solid-coloured clothes. Songlian also follows this fashionable wave. Her clothing change to red, claret, and other slightly more refined cheongsams soon after she joins the wealthy family.

This costume changing process reflects a girl's development into a woman in a traditional Chinese context, which is an unavoidable experience for almost all women in China. Women lost the freedom they had enjoyed since taking off their student uniforms. Meanwhile, the heavily saturated cheongsam signifies vanity, desire, and grandeur, whereas the student outfit symbolises innocence and liberty [9]. The alternation in Songlian's clothes emphasises the sadness of the feudal time.

\section{AUDIO}

Non-diegetic sound and diegetic sound are both 
crucial points of audio in Raise the Red Lantern. The main principal components of background music are several diverse genres of Chinese indigenous pure music created by Chinese traditional musical instruments (e.g., Chinese drums, Erhu) and chorus in this film. Additionally, the uses of diegetic sound are mainly the interplay of Peking Opera sang by the third concubine and the dynamic sound. Both generate multiple indicative connotations and suggests a range of interpretations [10]. At the same time, these sounds resonate a visceral chord with audiences.

\subsection{Non-diegetic Sound}

The polyphonic percussion exchanges include layered and asynchronous sounds that occur punctually when the red lanterns are lit. It is appropriate for these sequences to convey a joyful and exuberant attitude to the audience. Chinese nationalised music has specific diversity, especially in mode, tonality, and rhythm. Furthermore, a rhythmic percussion section can be heard on each seasonal display, a traditional percussion sound that provides a tense, intense listening experience, which also complements the montage editing [11]. The orchestra also accompanies the lighting of the lanterns as the concubines are carried by servants to the inner chamber, or as they wait at the door for their husband to choose which woman would stay in his room for the night. In general, the soundtrack is accompanied by the rapid pace of the servants and the intense struggle for favour between these wives, which becomes an important part of the narrative in each section of the film.

These folk percussions playing non-diegetic sound represents the historical and traditional Chinese culture, giving audiences a domestic atmosphere from the audio perspective, which is more directly and supplementary to the plot and images at the same time. It is always an indicative symbol of a director's approach, which contributes to the film aesthetics and communication.

\subsection{Diegetic Sound}

First, the Peking Opera symbolises Chinese folk culture. The excerpts from Peking Opera match the courtyard and give the audience a dual experience which includes aural and visual conditions. In addition, one of the most significant kinetic effects in the film is the sound of the pounding of feet, which becomes a symbol of favour and power in the household, as the wife or concubine who has been awarded the lighting of the lanterns is allowed to pound her feet. The use of feettapping is also exaggerated and amplified, as the sound of feet-tapping floats over the courtyard, not only on the feet but also on the hearts of the other unprivileged ladies [12].

The Peking Opera Sound decodes the Chinese characteristics directly, which is a symbol of historical traditional Chinese culture. It has the attribute of auditory culture communication. Additionally, the feet-tapping sound generates multiple connotations and suggests a range of interpretations that are a representation of the family class of these women, the secret rivalry between wife and concubines and a seemingly harmonious but contending family environment veritably.

\section{EDITING}

Editing is also another significant element of the symbolism of Raise the Red Lantern. It conveys inner messages and values. It also implies the relationship between female characters and traditional Chinese culture and promotes narrative development.

Seasonal montages with metaphorical representation are the framework of the film, which indicates the personal signatures of the director. Raise the Red Lantern is set in summer and lasts for a whole year, yet spring does not appear. Spring is a profoundly blessed and positive emblem in traditional Chinese culture, representing the renewal and blooming of life. And yet, spring is disappearing in this film, foreshadowing Songlian and other women falling into a dismal cycle in which they would lose the "spring" of their lives.

\section{CONCLUSION}

Film is both the carrier and content of the cultural transmission. As a medium of mass narrative, film is a visual and moving record of social reality, customs, ethnicity, and values, allowing audiences to perceive the fascination of diverse cultures during a film screening.

Raise the Red Lantern undertakes the significant mission of constructing the traditional national image and spreading the folk culture in both local and international context by virtue of these multimodal symbols. The ideology of Raise the Red Lantern demonstrates the stereotype of feudal Chinese society, in which the images of women are submissive, helpless, and vulnerable. Feminine self-objectification and self-negation remain for a long time under the historical patriarchal society. The representation of cultural transmission of Raise the Red Lantern is well-shown by these symbols, which deliver a comprehensive perspective for audiences to get cognition and understanding of the cultural and social condition.

\section{REFERENCES}

[1] B. Stepanov, “Coming Soon?": Cinematic Sociology and the Cultural Turn, in: Russian Sociological Review, 2020, pp.152-154. DOI: 10.17323/1728-192x-2020-4-152-177

[2] Q. Yan, The Aesthetic Analysis of Raise the Red Lantern, in: Journal of News Research, Vol. 11, 
No. 11, 2020, pp.91-92. DOI: 1674-8883 (2020)

11-0091-02

[3] Y. Luo, The Analysis of the artistic language of Raise the Red Lantern, in: Journal of Xinxiang University, Vol. 35, No. 7, 2018, pp. 49-52.

[4] Q. Cheng, A Multimodal Discourse Analysis of the Motif of Decadent Feudal Culture in the Movie Raise the Red Lantern, in: Literary Theory, 2011, pp.34-36.

[5] J. Loeb, Dissonance Analysis Rising: Subversive Sound in Zhang Yimou's Raise the Red Lantern, in: Film Philosophy, 2011, pp. 204-219.

[6] H. Raleigh, Film: The Revival of Aesthetic Symbolism, in: The Journal of Aesthetics and Art Criticism, Vol. 32, No. 2, 1973, pp. 219-227. DOI: https://doi.org/10.2307/429039

[7] J. Hu, The Research on the Application of Colours of Raise the Red Lantern, in: Journalism Studies Journal, 2020, pp. 104-105. DOI: 16748883(2020)24-0104-02

[8] Y. Li, The Analysis of Colour and Artistic Conception of Raise the Red Lantern, in: Mome Literature, 2013, pp. 144-145.

[9] G. Wang, The Interpretation of Costume Language of Raise the Red Lantern, in: Mangzhong Literature, 2012.

[10] Z. Li, Resistance and Tragedy: the Coding and Construction from Fictionto Film: Taking" Raise the Red Lantern" as an Example, in: Journal of Sanming University, 2017.

[11] Q. Yan, The Sound Analysis of Raise the Red Lantern, in: Journal of News Research, 2020.

[12] Q, Yue, The Analysis of Sound Characteristic of Raise the Red Lantern, in: PCSF, 2020, pp. 110-112. DOI: 10.16607/j.cnki.1674-6708.2020.21.035 